\title{
THE HEMODYNAMIC EFFECTS OF HYPOTENSIVE DRUGS IN MAN. III. HEXAMETHONIUM 1, 2, 3
}

\author{
By EDWARD D. FREIS, JOHN C. ROSE, EDWARD A. PARTENOPE, THOMAS F. \\ HIGGINS, ROBERT T. KELLEY, 4 HAROLD W. SCHNAPER, AND \\ ROBERT L. JOHNSON
}
(From the Cardiovascular Research Laboratory, Georgetown University Hospital, the Depart- ment of Medicine, Georgetorem University School of Medicine, and the Veterans Administration Hospital, Washington, D. C.)

(Submitted for publication July 7, 1952; accepted August 14, 1953)

While searching for derivatives of d-tubocurarine, Barlow and Ing (1) and Paton and Zaimis (2) independently synthesized a series of polymethylene bistrimethylammonium salts. The latter investigators demonstrated that the pharmacological properties of this series were related to the length of the polymethylene chain; the decacompound produced neuromuscular block while the penta and hexa-compounds prevented the transmission of impulses across the synapses in all autonomic ganglia. They also carried out preliminary trials in man (3) but Arnold and Rosenheim were the first to use these agents in hypertension (4). Finally, Restall and Smirk demonstrated that it was possible to reduce blood pressure and obtain clinical improvement in hypertensive patients for long periods by the use of repeated parenteral doses of hexamethonium (5).

Studies in this laboratory have confirmed the observations of Restall and Smirk and in addition have shown the potentiating effect of 1-hydrazinophthalazine (Apresoline) when alternated with doses of hexamethonium in patients with hypertension $(6,7)$. Our studies also suggested that hexamethonium may be useful in the treatment of

1 Supported in part by research grants from the National Heart Institute, U. S. Public Health Service, the Squibb Institute for Medical Research, New Brunswick, New Jersey, Irwin, Neisler and Company, Decatur, Illinois and Ciba Pharmaceuticals, Summit, New Jersey.

2 Sponsored (in part) by the VA and published with the approval of the Chief Medical Director. The statements and conclusions published by the authors are a result of their own study and do not necessarily reflect the opinion or policy of the Veterans Administration.

${ }^{3}$ Hexamethonium dibromide (Bistrium) was supplied by H. Sidney Newcomer, M.D., E. R. Squibb and Sons, New York, New York.

4 Research Fellow-Washington, D. C., Heart Association. acute peripheral vascular disorders associated with neurogenic vasospasm as well as in the evaluation of the sympathetic vasoconstrictor component in cases of peripheral vascular disease (8). Since from these previous studies it appeared that hexamethonium was a potent agent both for reducing blood pressure and increasing foot and digital blood flow a more complete analysis of its hemodynamic effects seemed indicated.

\section{METHODS}

The subjects were 25 hypertensive patients admitted to the wards of Georgetown University Hospital and the Veterans Administration Hospital and four normotensive young males (medical students). Hexamethonium was administered intravenously at a rate of 1 to $2 \mathrm{mg}$. per minute for the first $15 \mathrm{mg}$. and then at a rate of 5 mg. per minute, in all instances until a significant hypotensive effect had been obtained or until 50 to $100 \mathrm{mg}$. had been administered. All dosages refer to the amount of hexamethonium ion administered.

The methods used in this investigation were essentially similar to those described in a previous communication (9), with the following exceptions: the determination of arteriovenous oxygen difference were carried out using the spectrophotometric method of Hickam and Frayser (10). The oxygen content of the expired air was determined using a Pauling type oxygen analyzer. ${ }^{3}$ The total peripheral resistance was calculated according to the method of Green, Lewis, Nickerson, and Heller (11). In the muscle blood flow experiments it was necessary to estimate the mean arterial pressure from the values for systolic and diastolic pressure as determined by the auscultatory method. The formula used was as follows: mean arterial pressure $=.436$ (pulse pressure) + diastolic pressure (12). Calf blood flow was measured as previously described except that a strain gage, ${ }^{8}$ with a car-

B Model C, Arnold O. Beckman, Inc., South Pasadena, California.

- Model P-23-B, Statham Laboratories, Beverly Hills, California. 
rier-wave type amplifier and direct writing oscillograph,? replaced the Brodie's bellows apparatus. Glomerular filtration rate was determined by the clearance of sodium thiosulfate (13).

\section{RESULTS}

\section{Cardiac function}

\section{Cardiac output, mean arterial pressure and total peripheral resistance}

The changes in cardiac output and total peripheral resistance seemed to vary with the state of cardiac compensation. In the hypertensive patient with a compensated heart the usual response to hypotensive doses of hexamethonium was a slight decrease in cardiac output. Thus, in 11 posttreatment analyses carried out in six patients without heart failure the cardiac output decreased by 6 to 38 per cent (mean 22.0 per cent, S.D. 9.3) (Table I, Cases 1 through 6 ). The decrease in mean arterial pressure was of similar magnitude varying from 10 to 37 per cent (mean 23.5 per cent, S.D. 7.0). In only one instance did the arterial pressure fall to normotensive levels. The total peripheral resistance did not change significantly varying between +19 and -22 per cent (mean -1.3 per cent).

In contrast, in four additional patients with congestive heart failure and one with malignant hypertension there was a significant increase in cardiac output in three and a slight increase in two patients following hexamethonium. The range for nine post-treatment determination was +3 to 100 per cent and the mean 38 per cent, S.D. 35.4 (Table I, Cases 7 through 11). In these instances the total peripheral resistance fell significantly the range being 27 to 70 per cent and the mean 47 per cent, S.D. 14.1.

\section{Other aspects of cardiac function}

The heart rate usually increased moderately after hexamethonium. There were insignificant changes in rate in three patients, slowing in one and rises in six cases; the average increase was 14 beats per minute (Table I).

Pressures on the right side of the circulation were measured in seven patients and decreased in all instances. In the group with compensated

\footnotetext{
${ }^{7}$ Model 140-C, Sanborn Company, Cambridge, Massachusetts.
}

hearts the pulmonary arterial pressure decreased in patient $W$. C. from $26 / 14$ to $14 / 8 \mathrm{~mm}$. $\mathrm{Hg}$. In patient $B$. J. the right ventricular pressure decreased from $38 / 12$ to $22 / 4 \mathrm{~mm}$. $\mathrm{Hg}$ (Figure 1). In subject $C$. A., the mean right auricular pressure decreased from -0.5 to $-2.5 \mathrm{~mm}$. $\mathrm{Hg}$. In the decompensated patients the pulmonary arterial pressure decreased in patient $T$. $P$. from $45 / 22$ to $20 / 12 \mathrm{~mm}$. $\mathrm{Hg}$ and in subject R. S. from $70 / 40$ to $40 / 15 \mathrm{~mm}$. Hg. The right ventricular pressures fell in subject J. C. from $115 / 25$ to $85 / 18$ $\mathrm{mm}$. $\mathrm{Hg}$ and in subject A. C. from $130 / 20$ to $80 / 8$ $\mathrm{mm}$. Hg. The decline in right heart pressures paralleled the fall in systemic arterial pressure.

\section{Blood Flow Through Various Regions}

Blood flow through the muscles (calf blood flow)

In a previous communication it was pointed out that a ten-fold increase in foot (primarily skin) blood flow occurred after hexamethonium (14). In the calf segment (primarily muscle) an increased blood flow as determined by the plethysmographic method also was observed but to a much smaller degree than that observed in the foot (Table II).

Ten hypertensive patients were studied. Two patients in the malignant phase had previous therapy with hexamethonium while the remaining eight were patients with essential hypertension who had received no previous treatment with hexamethonium. In the latter eight cases all exhibited an increase of muscle blood flow varying from 11 to 61 per cent (mean 39.4 per cent) of the control values. The crude peripheral resistance decreased by 26 to 56 per cent (mean 40.4 per cent). The increase of blood flow began simultaneously with the decrease of blood pressure and some increase persisted for at least an hour.

The two patients who had malignant hypertension and who had been under continuous dosages of hexamethonium immediately prior to testing showed a decrease of blood flow in one instance and no change in the other. It could not be determined from this limited data whether these atypical responses were associated with the development of tolerance to the vasodilating properties of the drug or represented a response peculiar to patients in the malignant phase of hypertension. 
HEXAMETHONIUM : HEMODYNAMIC EFFECTS

(1)

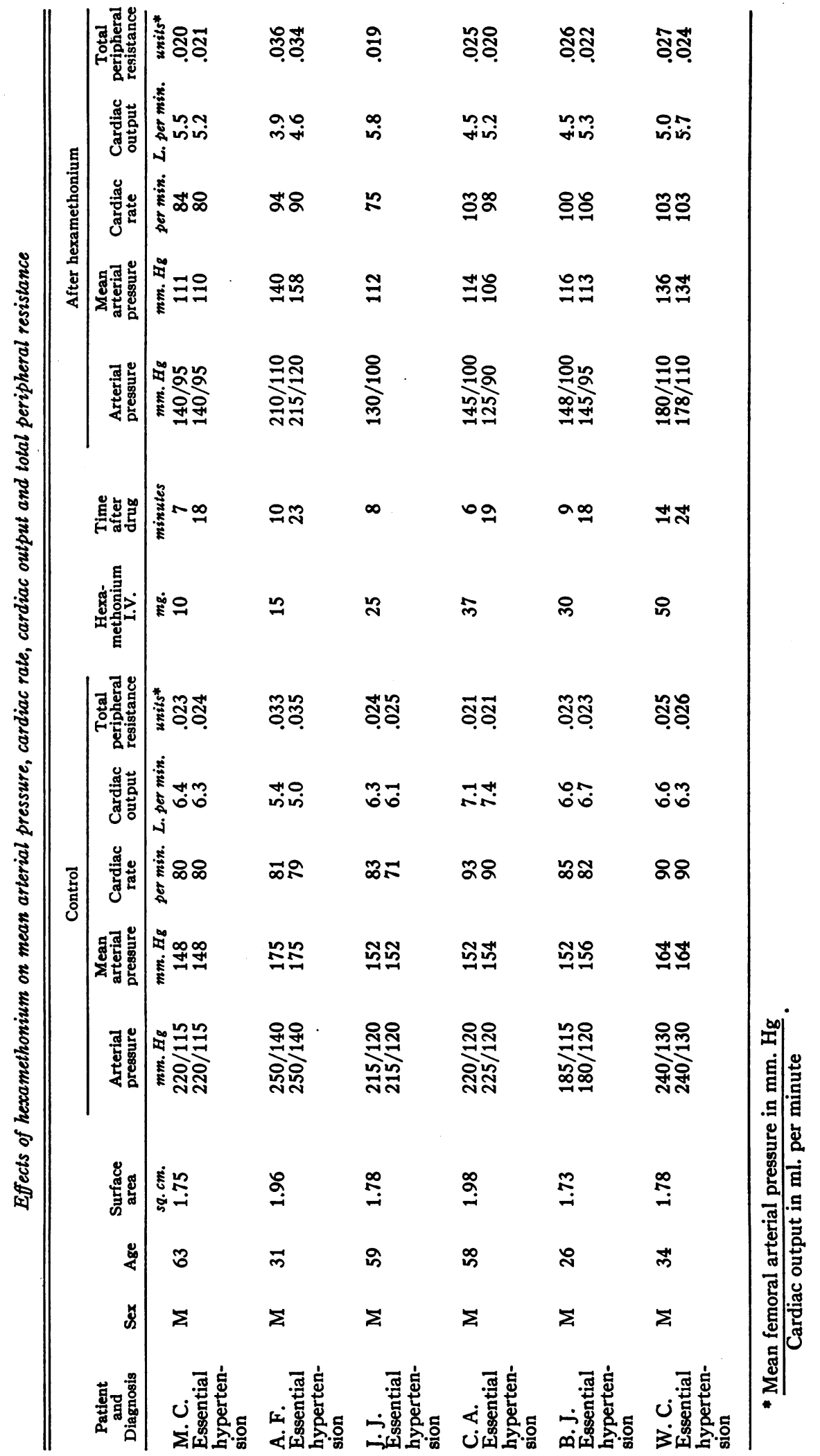


FREIS, ROSE, PARTENOPE, HIGGINS, KELLEY, SCHNAPER, AND JOHNSON

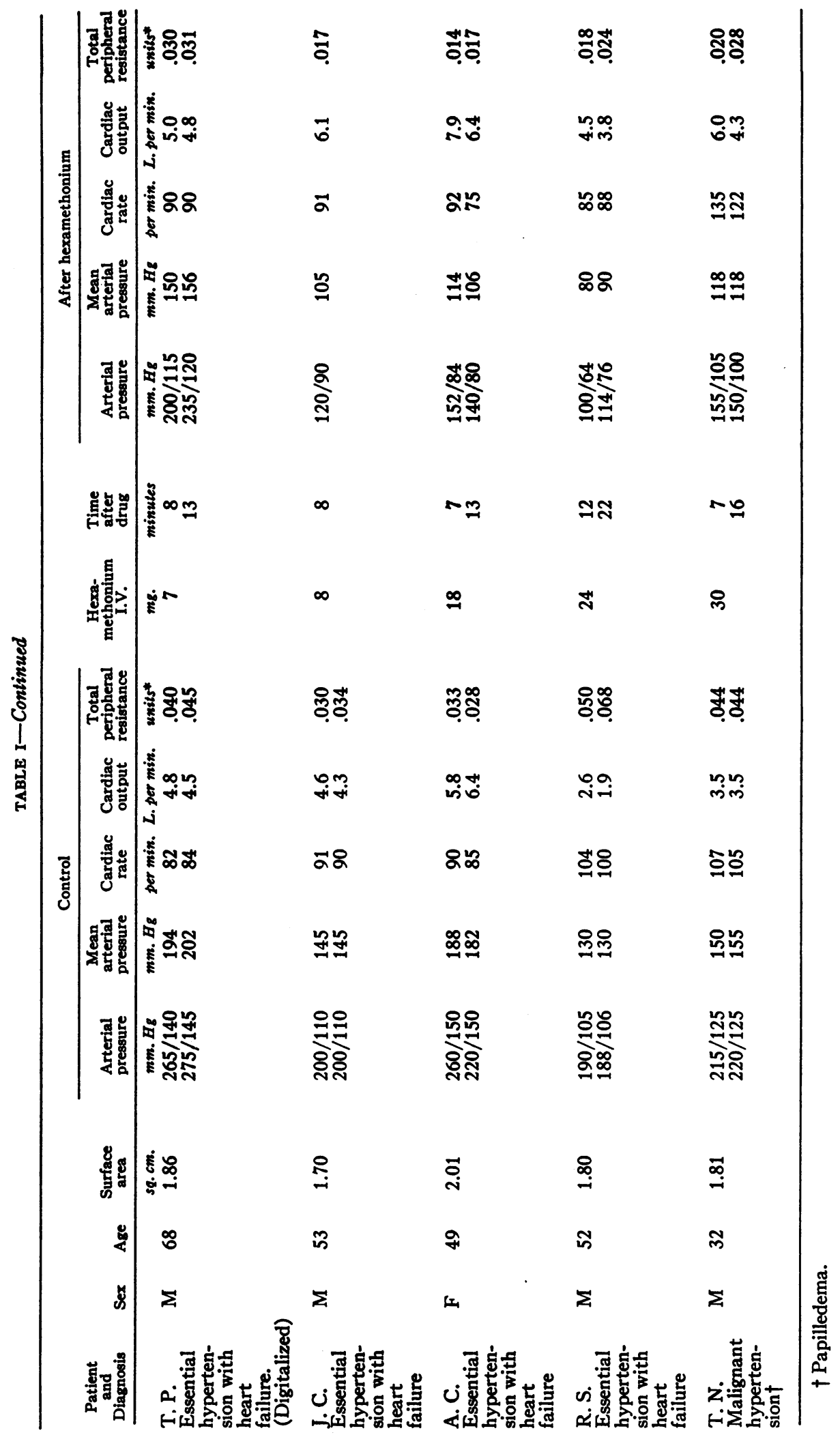




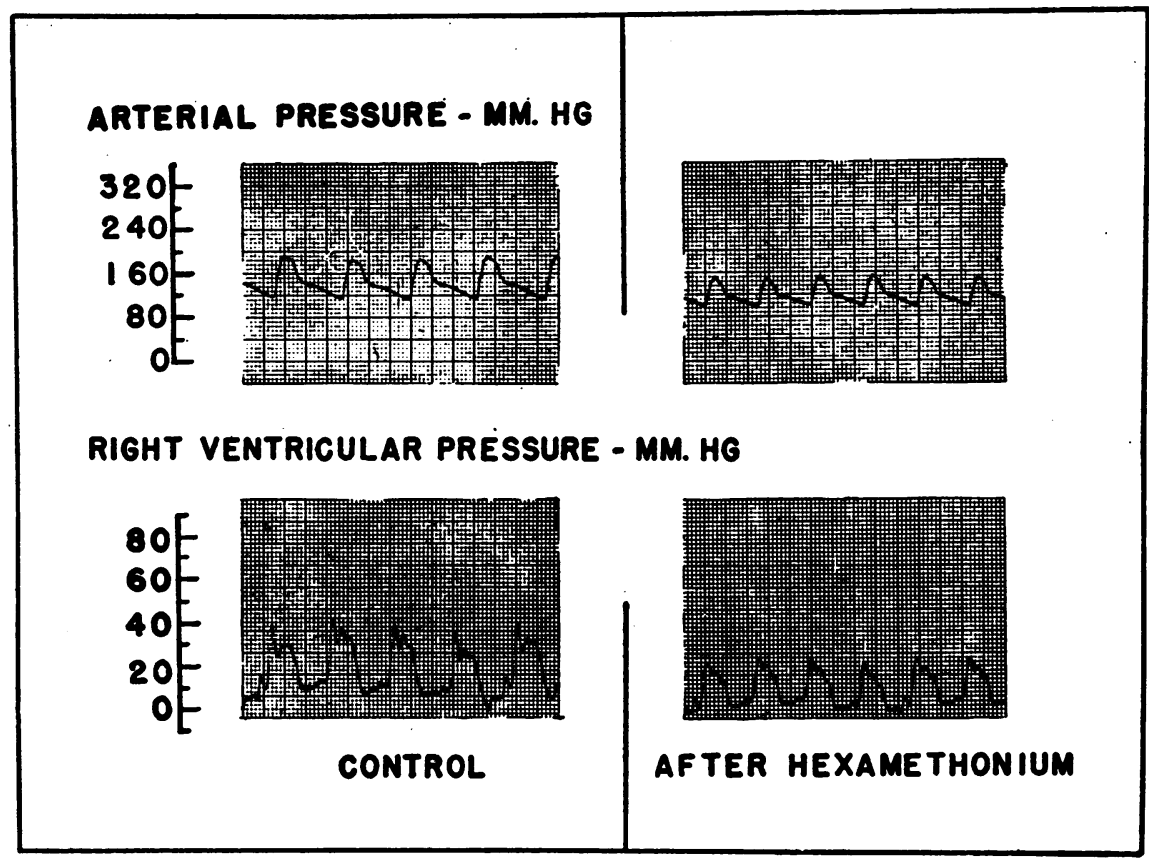

Fig. 1. Cuttings Taken from the Recordings of Systemic Arterial (Above) and Right Ventricular Pressures (Below) in Patient B. J. before and 19 Minutes after the Intravenous Administration of 30 mg. of Hexamethonium

The reduction of arterial pressure was accompanied by a considerable decrease of right ventricular pressure. See text and Table I for further details.

\section{Blood flow through the hepatic-portal circuit}

Determinations of estimated hepatic-portal blood flow were carried out in five hypertensive and two normal subjects. In all of the hypertensive patients the mean arterial pressure decreased following hexamethonium, the range being 20 to 40 per cent and the mean 28 per cent (Table III). In four cases estimated hepatic blood flow decreased by 8 to 54 per cent (mean 25 per cent) while in the remaining case it was unchanged. The hepatic-portal vascular resistance fell in all except one of the hypertensive patients.

One of the normal subjects exhibited insignificant changes in estimated hepatic portal flow and peripheral vascular resistance while in the remaining subject hepatic blood flow decreased 19 per cent and peripheral resistance also was reduced slightly. Thus in four or five hypertensive and one of two normotensive subjects the estimated hepatic portal blood flow decreased moderately and in the remaining two cases did not change significantly.

\section{Blood flow through the kidneys}

Two of the seven cases studied exhibited no significant change in renal blood flow (D. G. and H. B., Table IV). However, changes in arterial pressure also were insignificant in these two subjects despite relatively high doses of hexamethonium. In the remaining five cases there was a reduction of renal plasma flow which paralleled the fall in arterial pressure (Table IV and Figure 2). However, in four of these cases all of whom were hypertensives, the renal plasma flow returned to or above the control levels after periods varying from 15 to 50 minutes following the time of drug administration. In all four instances the plasma flow rose despite a continued significant reduction of arterial pressure. In the remaining case, a normal subject, the plasma flow remained reduced up to 50 minutes after hexamethonium. Thus, the usual pattern of response to hypotensive doses of hexamethonium was an early decrease in renal plasma flow followed by a return to control values despite continued reduction of arterial pressure. 


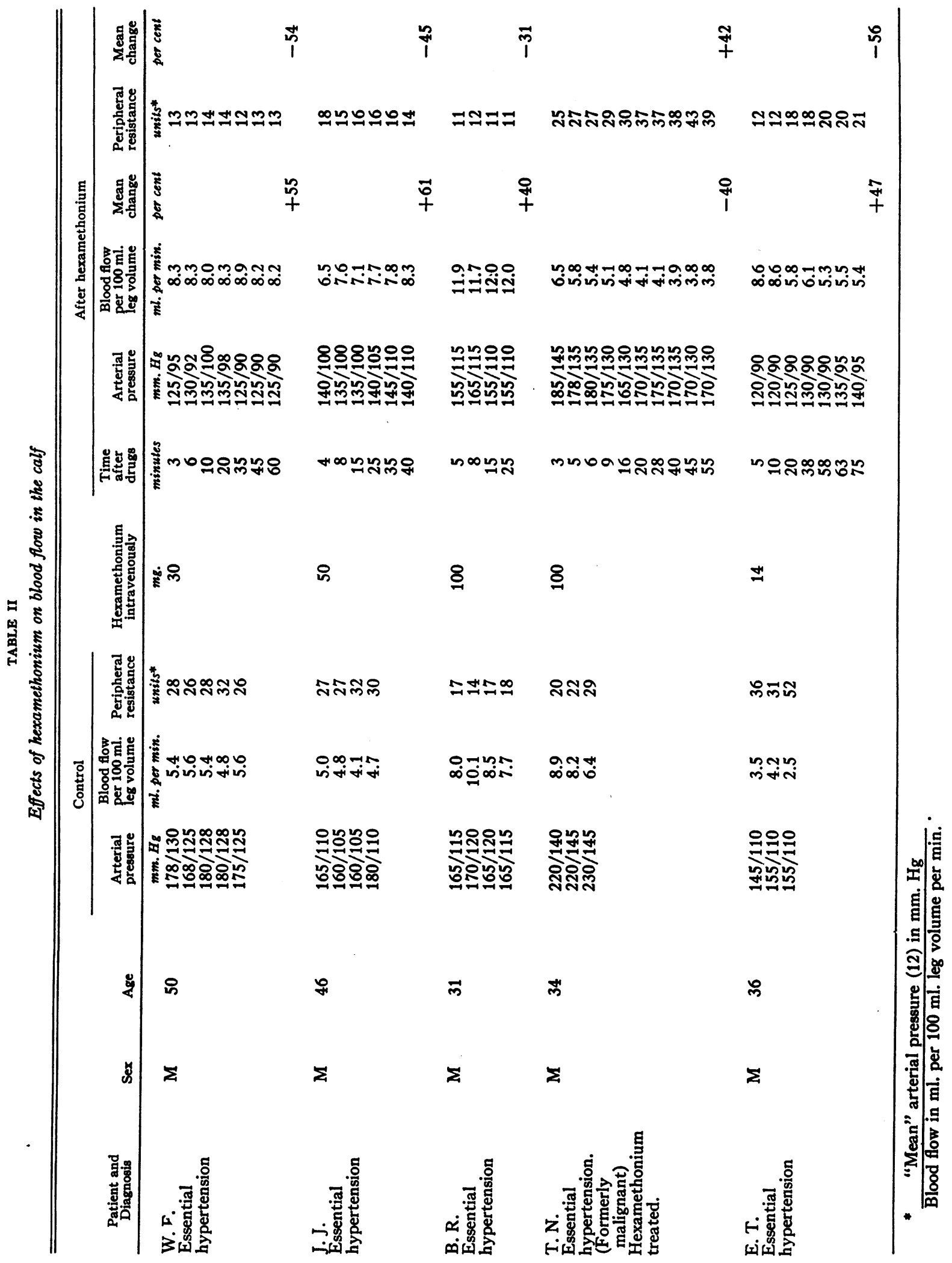


HEXAMETHONIUM : HEMODYNAMIC EFFECTS

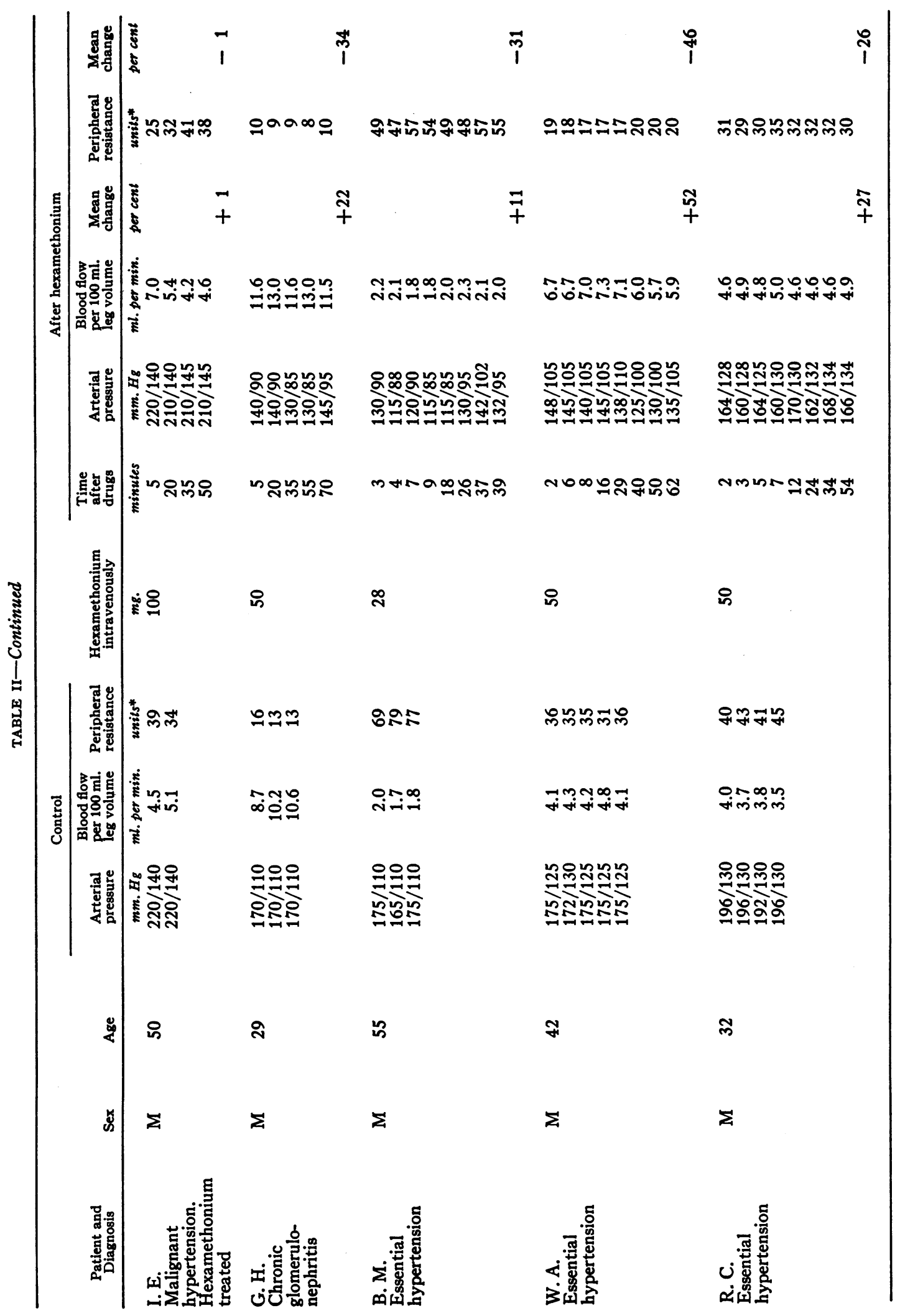




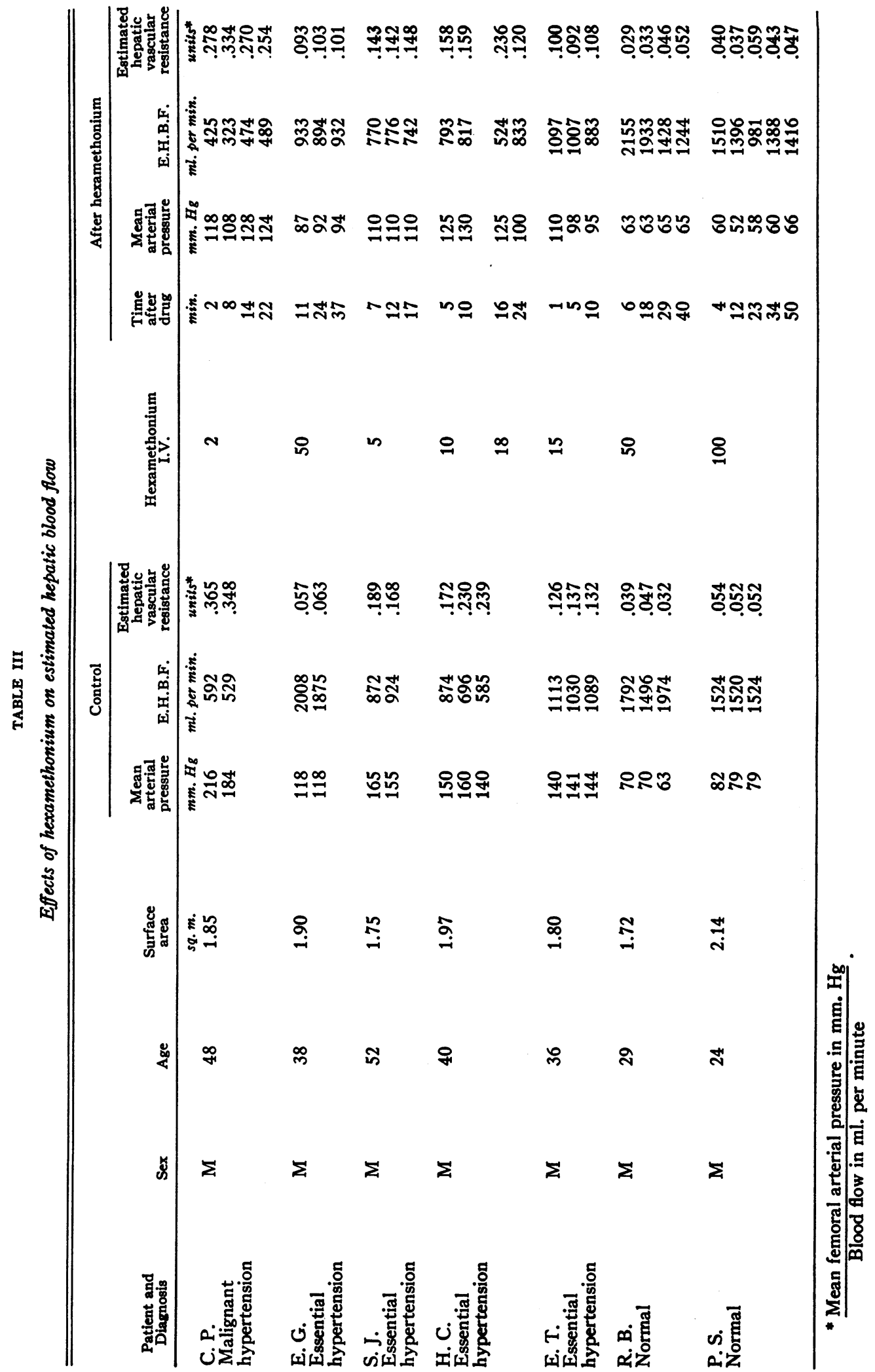


HEXAMETHONIUM: HEMODYNAMIC EFFECTS

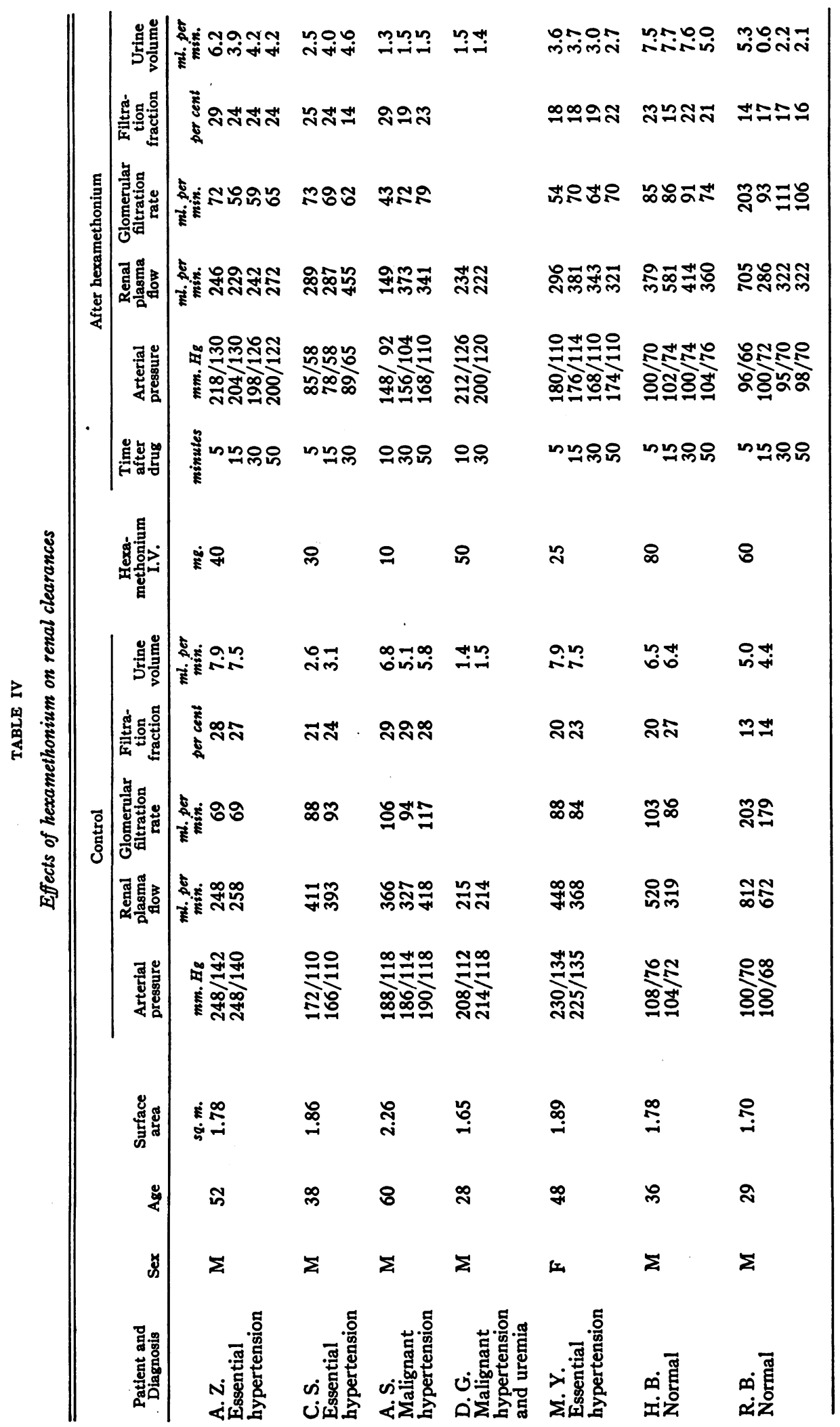




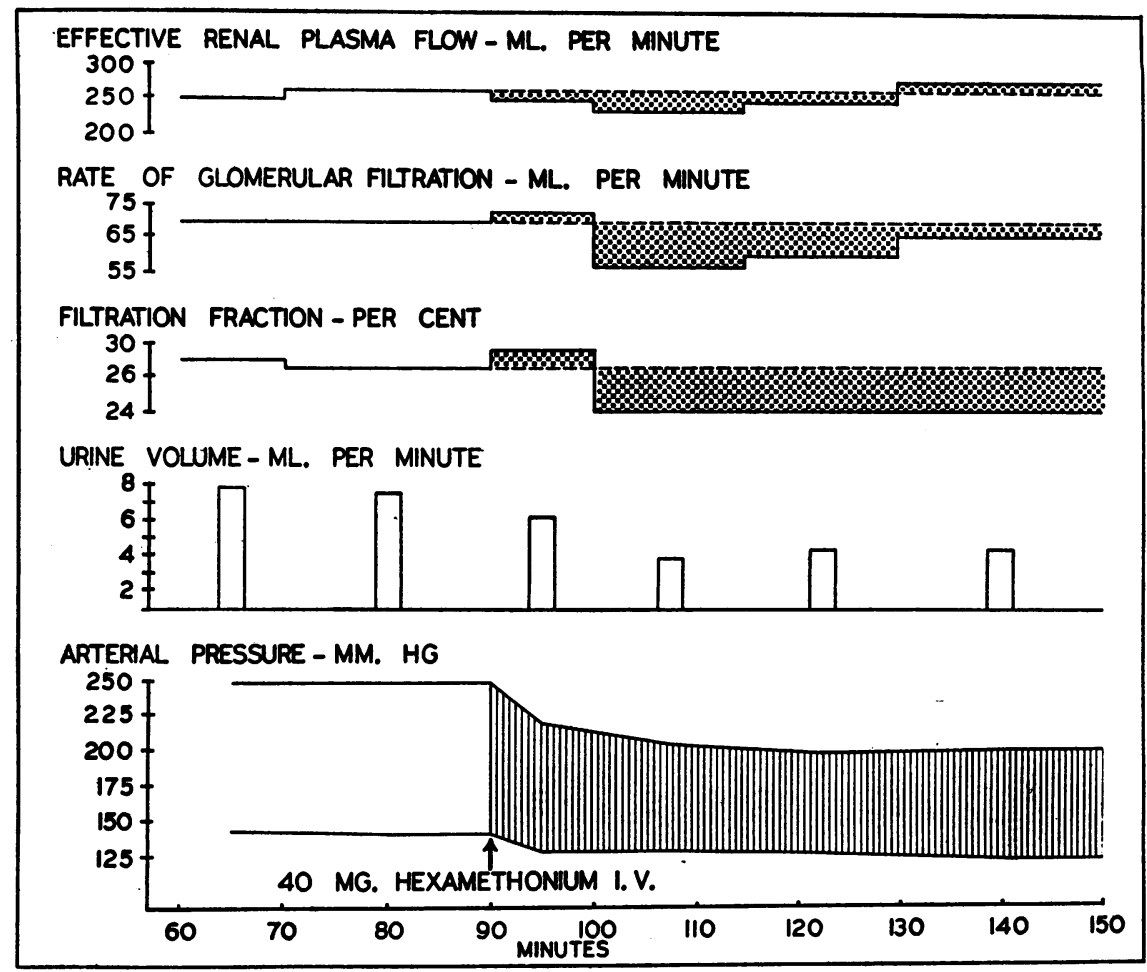

Fig. 2. Chart of Effective Renal Plasma Flow, Glomerular Filtration Rate, Filtration Fraction, Urine Volume and Arterial Pressure before and after the Intravenous Administration of $\mathbf{4 0}$ mg. of Hexamethonium Ion in Patient A. Z.

In the early period there was a decrease in renal plasma flow, glomerular filtration rate and urine volume. However, 45 minutes after hexamethonium renal plasma flow had returned to and glomerular filtration rate approached control values despite continued significant reduction in filtration fraction, urine volume and arterial pressure.

\section{Other Aspects of Renal Function}

Glomerular filtration rate was determined in six of the subjects listed in Table IV. In three hypertensive patients there was a reduction of glomerular filtration rate followed by a rise toward but not to the control values (A. Z., A. S., and M. Y., Table IV and Figure 2). In one hypertensive and one normal subject there was a continued fall in glomerular filtration rate throughout the experimental period. The final normal subject who had exhibited no significant change in arterial pressure or renal blood flow also showed no change in glomerular filtration rate. It was apparent, therefore, that the rate of glomerular filtration decreased paralleling the blood pressure fall and complete compensation usually did not occur during the experimental period. The filtration fraction decreased in all of the hyperten- sive patients. In the two normal subjects there was no significant change in the patient who showed no reduction of arterial pressure and a slight rise in filtration fraction in the other.

The volume of urine flow did not change in the two cases who exhibited insignificant reduction of arterial pressure (D. G. and H. B., Table IV). Four of the five remaining cases exhibited a reduction of urine volume which persisted throughout the experimental period. The final patient (C. S.) exhibited a slight rise in urine volume.

\section{DISCUSSION}

Previous hemodynamic studies in this laboratory demonstrated that hexamethonium produces a marked to complete abolition of such vasoconstrictor reflexes as the vasopressor "overshoot" following the Valsalva maneuver, the cold pres- 
sor response and the reflex vasoconstrictions to "noxious" stimuli as determined by digital plethysmography (15). As would be expected following such inhibition of moderator reflexes by a ganglionic blocking agent the pressor responses to epinephrine and norepinephrine were augmented considerably, after as compared to before, hexamethonium (16). In a constant temperature cold room the increase in foot blood flow was as great following hexamethonium as after extradural or intrathecal anesthesia in normal subjects, suggesting nearly complete ganglionic blockade in man (14). In addition, probably by reason of the inhibition of vasoconstrictor reflexes, hexamethonium was found to induce marked hypotension in normal or hypertensive subjects following minor degrees of blood loss such as that occasioned by the brief application of venous tourniquets to the extremities or by small venesections of 250 to 500 cc. of blood (17). Thus, the previous studies demonstrated that hexamethonium in man interferes with transmission of sympathetic vasoconstrictor impulses more completely than any previously known agent. The present investigation has determined the effects of such widespread inhibition of sympathetic impulses on cardiovascular dynamics.

In the patients who did not exhibit congestive heart failure and whose cardiac outputs were in the normal range, the hypotensive response to hexamethonium was accompanied by a decreased cardiac output and little or no change in total peripheral resistance. These observations are in approximate agreement with those of Werkö, Frisk, Wade, and Eliasch (18), but are opposed to those of Gilmore, Kopelman, McMichael, and Milne (19) who found essentially no change in cardiac output after hexamethonium. Thus, the reduction of arterial pressure in the present series seemed to be secondary to a diminished cardiac output rather than to arteriolar vasodilation. The decreased cardiac output in turn appeared to be due to a failure of venous return since the pressures on the right side of the circulation were reduced uniformly.

The failure of venous return probably was produced by pooling of blood in the peripheral circulation. Such pooling could be due to (1) an increase in the total vascular capacity, and (2) the blockade of reflex vasoconstrictor responses (17).
By contrast in the patients with congestive heart failure or malignant hypertension the decreases in systemic and right heart pressures were accompanied by an increased cardiac output and decreased total peripheral resistance. These divergent observations in the patients with heart failure as compared to compensated subjects may be explained, however, in the light of the following considerations: first, in the case of the heart failure subjects the peripheral pooling of blood induced by hexamethonium would act like a venesection reducing the loading pressure of the congested right side of the heart thereby facilitating its recovery. Second, it is evident that patients with this type of heart failure are in a state of elevated vasoconstrictor tone since normal or elevated levels of systemic arterial pressure are maintained despite a cardiac output which usually is reduced. Hexamethonium by its blocking action on vasoconstrictor reflexes abolishes this increased tone thus permitting a decrease in total peripheral resistance and thereby also in the demand for cardiac work. These considerations and their implications in regard to the nature of congestive heart failure have been discussed more fully in another communication (20).

Muscle blood flows increased only moderately, while renal and hepatic-portal blood flows fell during the maximum action of the drug. Foot blood flow increased approximately ten fold (14) but since this vascular area is small in relation to the total vasculature the decrease in vascular resistance in the foot had little influence on the total peripheral resistance. These results suggest that there is an uneven distribution of sympathetic vasocontrictor nerves in different vascular areas. Only in a single region, the distal parts of the extremities, was a marked increase in flow observed. In the other and larger vascular areas (muscles, hepatic-portal and renal vascular beds) moderate increases or actual decreases in flow occurred while the total peripheral resistance usually was only slightly reduced. These data do not support the view that the sympathetic vasoconstrictor system is of great importance in regulating arteriolar tone in the resting, supine subject except for its role in temperature regulation of the skin particularly of the distal parts of the extremities. The results also emphasize the fallacies inherent in drawing conclusions as to the overall 
vasodilating effects of agents which increase skin temperature, color or blood flow.

The hemodynamic effects of hexamethonium, however, are due to more than simple inhibition of sympathetic vasoconstrictor nerves since the drug interferes with transmission through all autonomic ganglia. Vasodilator nerves which synapse in the ganglia as well as vasoconstrictor impulses will be inhibited. For example, blockade of vasodilator impulses is seen in the cessation of salivary flow following the drug (21). Thus, the results observed after hexamethonium may be in reality the net effect of combined inhibition of autonomic vasoconstrictor and vasodilator impulses.

The pattern of change in renal function was qualitatively similar to that observed after certain other hypotensive agents including veratrum viride (9), the dihydrogenated alkaloids of ergot (22) and sodium nitrite given as a single, oral dose (23). The renal vasculature did not share in the decrease in vascular resistance associated with the fall in arterial pressure. This is indicated by the fact that the renal plasma flow decreased sharply at the onset of the hypotensive response regardless of the drug used. However, as the arterial pressure stabilized at a lower level or began to rise the resistance of the renal vessels decreased to permit a return to normal rates of plasma flow. This effect, which was first observed by Smith and his co-workers folowing spinal anaesthesia, has been interpreted by him as indicating an autonomy of the renal arterioles (24).

A recent study by Machinnon indicated that the closely related compound, pentamethonium produced a decrease in renal blood flow in both normotensive and hypertensive subjects (25). However, the design of his experiments was such that only the early hypotensive response to the drug was studied. Thus, insufficient time was allowed to permit observation of the later return of renal plasma flow to control levels. Mills, Moyer, and Handley found no change in renal clearances following hexamethonium in normal subjects but observed some diminution in hypertensive patients (26).

As a result of the percentally greater fall in glomerular filtration rate than in plasma flow there was a decrease in filtration fraction which in hypertensive subjects approached normal values.
The urine during this period became quite concentrated suggesting that tubular function was not significantly impaired. This pattern of change has been observed with hypotensive agents of all types tested in this laboratory (23) and therefore probably is secondary to the sudden alteration of arterial pressure rather than to any specific action of individual drugs on the kidney.

From the point of view of effects on hemodynamics the response to hexamethonium does not appear to be entirely desirable. Thus, cardiac output may decrease, renal clearances especially glomerular filtration rate fall at least temporarily and homeostatic, vasomotor reflexes are seriously compromised. However, despite these apparently undesirable. and abnormal acute actions, the clinical response to hexamethonium frequently has appeared to be beneficial $(5,7,8)$. These correlative clinical and experimental studies emphasize the fact that the results of hemodynamic analysis need not always indicate the desirability of a given agent in clinical practice where other factors may determine the usefulness of the drug.

\section{SUMMARY AND CONCLUSIONS}

Hexamethonium administered to hypertensive and normal subjects produces the following hemodynamic effects:

1. In hypertensive patients who do not have cardiac decompensation the reduction of systemic arterial pressure is accompanied by a decrease in right heart pressures and cardiac output. The total peripheral resistance does not change significantly. It is suggested that these alterations are the result of a combination of "venous pooling" and failure of reflex vasoconstriction.

2. In patients with heart failure the fall in systemic arterial pressure appears to be accompanied by a reduction of right heart pressures, an increase in cardiac output and a significant decrease in total peripheral resistance. These alterations may be due to unloading of the congested right side of the heart as well as to inhibition of vasoconstrictor reflexes activated by the low output heart failure.

3. In contrast to the marked increase in blood flow in the foot observed previously, blood flow through the muscles increases only moderately. Since the arterial pressure falls after hexametho- 
nium a significant decrease in peripheral resistance is assumed to occur in this area.

4. Despite a moderate reduction of hepatic vascular resistance estimated hepatic-portal blood flow usually decreases after hexamethonium.

5. Renal plasma flow decreases paralleling the initial fall in arterial pressure and then rises to approximate control levels despite a continued hypotensive response. This is consistent with previous observations indicating an autonomy of tone of the renal arterioles.

6. In most cases the changes in glomerular filtration rate follow a pattern similar to the alterations in renal plasma flow, but occasionally filtration may remain below control values. Oliguria with increased concentration of urine usually occurs. All of these renal effects begin to diminish after 30 to 60 minutes despite continued significant hypotension.

7. The studies to date suggest that sympathetic vasoconstrictor nerves blocked by hexamethonium exert the controlling influence on homeostatic adjustments to postural change as well as in maintaining the tone of the vessels of the distal part of the extremities. However, in resting supine subjects such nerves appear to exert a much less important influence on arteriolar tone in the hepatic-portal, renal and muscle areas.

\section{ACKNOWLEDGMENT}

The authors wish to thank Miss Jean Pietras for valuable technical assistance.

\section{REFERENCES}

1. Barlow, R. B., and Ing, H. R., Curare-like action of polymethylene bisquaternary ammonium salts. Nature, 1948, 161, 718.

2. Paton, W. D. M., and Zaimis, E. J., Clinical potentialities of certain bisquaternary salts causing neuromuscular and ganglionic block. Nature, 1948, $162,810$.

3. Organe, G., Paton, W. D. M., and Zaimis, E. J., Preliminary trials of bistrimethylammonium decane and pentane diiodide ( $\mathrm{C} 10$ and $\mathrm{C} 5$ ) in man. Lancet, 1949, 1, 21.

4. Arnold, P., and Rosenheim, M. L., Effect of pentamethonium iodide on normal and hypertensive persons. Lancet, 1949, 2, 321.

5. Restall, P. A., and Smirk, F. H., The treatment of high blood pressure with hexamethonium iodide. New Zealand M. J., 1950, 49, 206.
6. Freis, E. D., Methonium compounds in hypertension. Letter to the editor. Lancet, 1951, 1, 909.

7. Freis, E. D., Finnerty, F. A., Jr., Schnaper, H. W., and Johnson, R. L., The treatment of hypertension with hexamethonium. Circulation, 1952, 5, 20.

8. Finnerty, F. A., Jr., and Freis, E. D., Clinical appraisal of hexamethonium (C6) in peripheral vascular diseases. New England J. Med., 1951, 245, 325.

9. Freis, E. D., Stanton, J. R., Culbertson, J. W., Litter, J., Halperin, M. H., Burnett, C. H., and Wilkins, R. W., The hemodynamic effects of hypotensive drugs in man. I. Veratrum viride. J. Clin. Invest., 1949, 28, 353.

10. Hickam, J. B., and Frayser, R., Spectrophotometric determination of blood oxygen. J. Biol. Chem., 1949, 180, 457.

11. Green, H. D., Lewis, R. N., Nickerson, N. D., and Heller, A. L., Blood flow, peripheral resistance and vascular tonus, with observations on the relationship between blood flow and cutaneous temperature. Am. J. Physiol., 1944, 141, 518.

12. Böger, A., and Wezler, K., Die Bestimmung des arteriellen Gasamtwiderstandes am Menschen. Arch. f. exper. Path. u. Pharmakol., 1937, 186, 43.

13. Pitts, R. F., Lotspeich, E. D., Schiess, W. A., and Ayer, J. L., Renal regulation of acid-base balance in man. I. Nature of the mechanism for acidifying urine. J. Clin. Invest., 1948, 27, 48.

14. Schnaper, H. W., Johnson, R. L., Tuohy, E. B., and Freis, E. D., The effect of hexamethonium as compared to procaine or metycaine lumbar block on the blood flow to the foot of normal subjects. J. Clin. Invest., 1951, 30, 786.

15. Finnerty, F. A., and Freis, E. D., Experimental and clinical evaluation in man of hexamethonium (C6), a new ganglionic blocking agent. Circulation, 1950, 2, 828.

16. Freis, E. D., MacKay, J. C., and Oliver, W. F., The effect of "sympatholytic" drugs on the cardiovascular responses to epinephrine and norepinephrine in man. Circulation, 1951, 3, 254.

17. Freis, E. D., Stanton, J. R., Finnerty, F. A., Jr., Schnaper, H. W., Johnson, R. L., Rath, C. E., and Wilkins, R. W., The collapse produced by venous congestion of the extremities or by venesection following certain hypotensive agents. J. Clin. Invest., 1951, 30, 435.

18. Werkö, L., Frisk, A. R., Wade, G., and Eliasch, H., Effect of hexamethonium bromide in arterial hypertension. Lancet, 1951, 2, 470.

19. Gilmore, H. R., Kopelman, H., McMichael, J., and Milne, I. G., The effect of hexamethonium bromide on the cardiac output and pulmonary circulation. Lancet, 1952, 2, 898.

20. Kelley, R. T., Freis, E. D., and Higgins, T. F., The effects of hexamethonium on certain manifestations of congestive heart failure. Circulation, 1953, 1, 169. 
21. Freis, E. D., Unpublished observations.

22. Freis, E. D., Stanton, J. R., Litter, J., Culbertson, J. W., Halperin, M. H., Moister, F. C., and Wilkins, R. W., The hemodynamic effects of hypotensive drugs in man. II. Dihydroergocornine. J. Clin. Invest., 1949, 28, 1387.

23. Freis, E. D., Stanton, J. R., Litter, J., Culbertson, J. W., Halperin, M. H., Moister, F. C., and Wilkins, R W., Hemodynamic effects of hypotensive agents in man. Am. J. Med., 1949, 7, 414.

24. Smith, H. W., Rovenstine, E. A., Goldring, W.,
Chasis, H., and Ranges, H. A., The effects of spinal anesthesia on the circulation in normal, unoperated man with reference to the autonomy of the arterioles, and especially those of renal circulation. J. Clin. Invest., 1939, 18, 319.

25. Machinnon, J., Effect of hypotension-producing drugs on the renal circulation. Lancet, 1952, 2, 12.

26. Mills, L. C., Moyer, J. H., and Handley, G. A., Effect of hexamethonium (C6) on renal hemodynamics. Laboratory and clinical evaluation. Am. J. Med., 1952, 13, 103. 